\title{
A new record of genus Zercon (Acari, Zerconidae) for Turkish Fauna: Zercon saphenus Blaszak, 1979
}

\author{
Rasit Urhan (Corresponding author) \\ Department of Biology, Faculty of Arts \& Sciences, Pamukkale University, Denizli, Turkey \\ E-mail: rurhan@pau.edu.tr \\ Elif Hilal Duran \\ Department of Biology, Faculty of Arts \& Sciences, Pamukkale University, Denizli, Turkey \\ E-mail: elifhilalduran@hotmail.com
}

\begin{abstract}
The zerconid mites collected from Kovada Lake National Park (Isparta province) in 20 March 2018 were evaluated. Collected samples were placed into plastic bags, labelled and transferred to the laboratory. Samples were placed into combined Berlese funnels and mites were extracted for 5-7 days according to their humidity. Mites were separated under a stereo-microscope. They were placed in $60 \%$ lactic acid for clearing and mounted onto permanent microscope slides using a glycerin medium. Then, the samples were put in stock bottles containing 70\% alcohol and 1- 3 drops glycine and labelled. Zercon saphenus was recorded as new for the Turkish mite fauna. Also, deutonymph and protonymph specimens of $Z$. saphenus were described for the first time from Turkey.
\end{abstract}

Keywords: Acari, Zerconidae, Zercon saphenus, Systematic, Turkey.

DOI: $10.7176 / \mathrm{JSTR} / 5-3-03$

\section{Introduction}

Mites are invertebrate animals belonging to class Arachnida of phylum Arthropoda, ranging in size from 0,1 to $10 \mathrm{~mm}$, living in debris and soil, in water, stored products, house dusts, plants and animals as internal and external parasites. The mites, which have a wide spreading range from the poles to the deserts, also show great differences in terms of body structure, size and behavior. Soil mites is one of the richest invertebrate groups in terms of both species richness and number of individuals in soil ecosystems (Ghilarov, 1963). There are many small arthropods in the litter on the forest floor. Most of them are mites (Hart et al. 1999). Mites form an 80\% group of among microarthropods in the soil fauna (Petersen and Luxton, 1982). Soil mites play an important role in soil biological efficiency by contributing to the decomposition of organic matter, the synthesis of humus, the protection of biological elements, and the stimulation of fungal and bacterial metabolism (Ghilarov, 1963).

Zerconid mites are important members of the soil fauna and they colonise in various soil substrates. Their idiosomal lenghts varying between $200-700 \mu \mathrm{m}$. These mites are weakly sclerotized and their life cycle include four active stages; larva, protonymph, deutonymph and adult. They are free-living and mostly associated with humus and soil, decomposed litter, leaf mould, plant parts, and among mosses (Urhan 2002, 2012, 2013). Zerconids are oligophagous predators and their diet include nematodes (Martikainen and Huhta, 1990). These small, predatory mites feed on the eggs, larvae and nymphs of other mites and springtails (Shereef and El Bishlawy, 1984).

The family Zerconidae is well known from the Holarctic region (Krantz, 1978). In present, approximately 40 genera which are comprised of more than 400 species are known worldwide. In Turkey, the first study of zerconids was published by Blaszak (1979) and further studies were made by Urhan and Ayyldiz (1994a, b; 1996a-e), and Urhan (1997, 1998a-b, 2001a-d, 2002, 2012, 2013), Karaca and Urhan (2015ab). Only two genera, Prozercon and Zercon, are known from Turkey (Karaca and Urhan, 2014). Until now, 81 Zercon species and 37 Prozercon species have been recorded from Turkey (Urhan and Karaca, 2019). 


\section{Materials and Methods}

The main material of this study is litter and soil samples collected from various habitats of Kovada Lake National Park (Isparta province) on March 20, 2018. Samples with mites were placed into plastic bags, labelled and transferred to the laboratory. Samples were placed into combined Berlese funnels, and mites were extracted for 5-7 days according to their humidity. Zerconid mites were separated under a stereomicroscope using a forceps, needle and pipette. They were placed in $60 \%$ lactic acid for clearing and mounted onto permanent microscope slides using a glycerine medium. Microscobic analyses were mainly made in environments containing glycerine. The examination of mites were done using an Olympus CX41 microscope with DP25 camera. After the analysed and identified of samples were photographed with a microscope and their shapes were drawn and different body parts were measured. Then, the samples were put in stock bottles containing $70 \%$ alcohol and 1 - 3 drops glycerine and labelled. The examined materials are deposited at the Acarology Laboratory of Pamukkale University, Denizli (Turkey). The terminology of setae follows that of Mašan \& Fend'a (2004). All measurements are given as mean, in micrometers $(\mu \mathrm{m})$.

\section{Results}

\subsection{Zercon saphenus Blaszak, 1979}

Material: Turkey, Isparta province, Eğirdir district, Kovada Lake National Park, $37^{\circ} 37^{\prime} 51^{\prime}$ ' N, 30 53' 49” E, 950 meters a.s.1.,, 20 March 2018. Samples of litter and soil underlying Juniperus sp., Pinus sp. and Quercus sp. collected by D. R. Bulut.

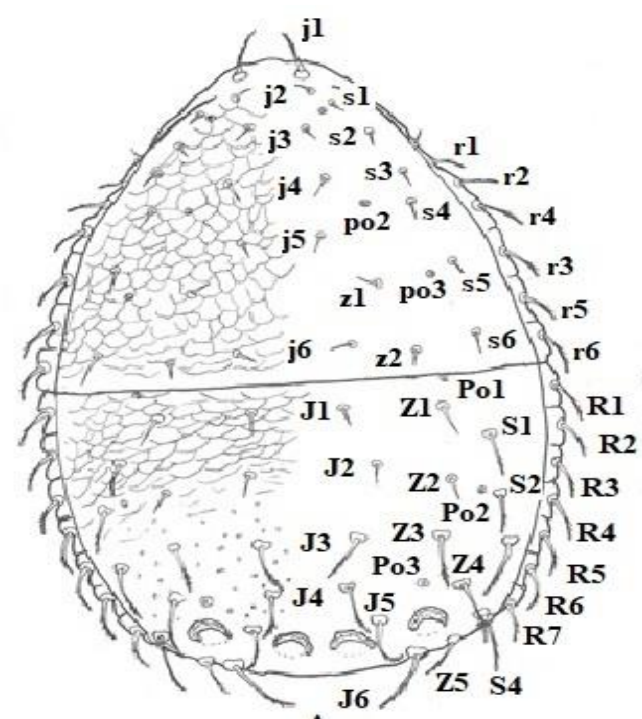

$\mathbf{A}$

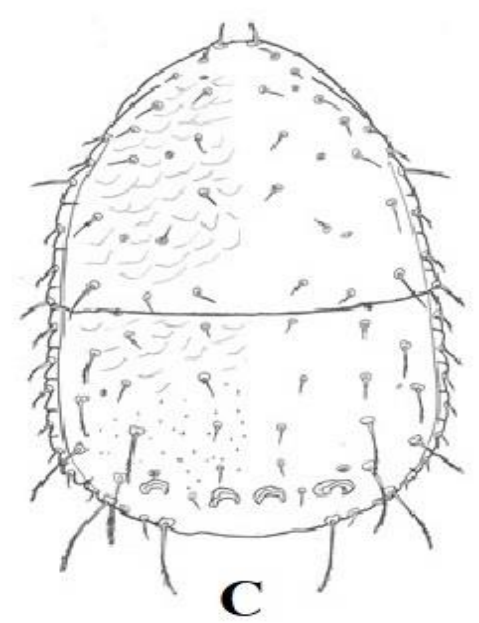

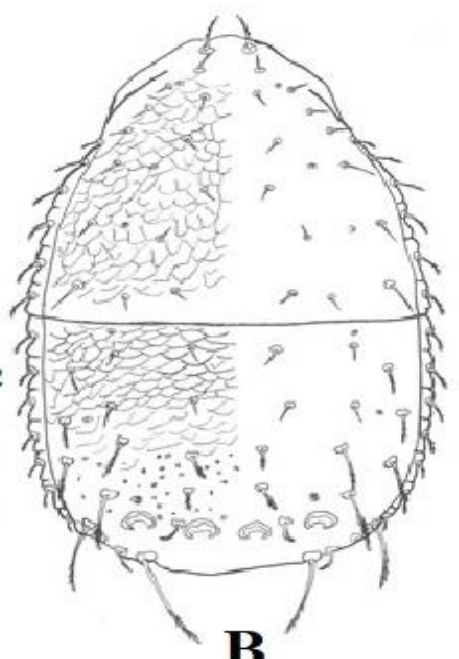

B

Figure 1. Dorsal views of Zercon saphenous specimens: A. Female, B. Male, C. Deutonymph, D. Protonymph 
Description of Female (Figure 1A)

Length of idiosoma 438-452 (445) / 300-325 (309) $\mu \mathrm{m}$.

Dorsum: Setae j1 finely barbed, r1-r7 barbed with hyaline endings and remaining setae on podonotum short and needle-like. Setae J1, J2, Z1 and Z2 short, smooth and needle-like, J3-J6, Z3-Z5 and S1-S4 barbed with hyaline endings on opistonotum. Setae J6 long, thickened, finely barbed and hyaline endings. Setae Z3 and Z4 similar to J3 and J4. Setae S3 reaching the margin of opistonotum. All R setae long, barbed and hyaline endings. The mean distance between the insertions of setae J6 is $110 \mu \mathrm{m}$. The mean distance between setae J6 and Z5 is $18 \mu \mathrm{m}$. Length of opisthonotal setae and distances between setae within longitudinal rows are as in Table 1 .

Pores: Pores po 1 near base of setae s1, po 2 on line connecting setae j4 and s4 and po 3 under the line connecting setae s5 and z1 on podonotum. Pores Po1 above base of setae Z1, Po2 on line connecting setae Z2 and S3, Po3 located under the line connecting setae J4 and Z4 nearer to seta Z4, Po4 under base of setae S4 on opistonotum.

Venter: Chaetotaxy and shape of the peritrematal shields are typical for the genus. Adgenital shields present. Anterior margin of the ventri-anal shield with 2 setae.

Male (Figure 1B)

Length of idiosoma 356-392 (375) / 234-256 (245) $\mu \mathrm{m}$. Dorsal side, ventral side, shapes of setae on idiosoma, and sculpture of podonotum and opisthonotum of male basically similar to that of female. The mean distance between the insertions of setae J6 is $102 \mu \mathrm{m}$. The mean distance between setae J6 and Z5 is $15 \mu \mathrm{m}$.

Deutonymph (Figure 1C)

Length of idiosoma 358-362 (360) / 228-250 (240) $\mu \mathrm{m}$. Setae j1, r4 and r7 long and finely barbed, remaining setae short and smooth on podonotum. Setae J6, Z3, Z4 and S1-S4 long, finely barbed and hyaline endings, remaining setae short and smooth on opistonotum. The mean distance between the insertions of setae $\mathrm{J} 6$ is $100 \mu \mathrm{m}$. The mean distance between setae J6 and Z5 is $15 \mu \mathrm{m}$.

Protonymph (Figure 1D)

Length of idiosoma 270-273 (272) / 184-188 (186) $\mu \mathrm{m}$. Setae j1 and r3 long and finely barbed, r3 with hyaline endings and remaining setae short and smooth on podonotum. Setae J6, Z3-Z4 and S1-S4 long, finely barbed and hyaline endings, remaining setae short and smooth on opistonotum. The mean distance between the insertions of setae $\mathrm{J} 6$ is $72 \mu \mathrm{m}$. The mean distance between setae $\mathrm{J} 6$ and $\mathrm{Z} 5$ is $16 \mu \mathrm{m}$.

Table 1. Length of opisthonotal setae and the distances between their bases in J, Z and S rows of female, male, deutonymph and protonymph specimens of Zercon saphenus (values as mean, in micrometers)

\begin{tabular}{|c|c|c|c|c|c|c|c|c|c|c|c|c|c|c|}
\hline Setae & q & $\hat{0}$ & DN & PN & Setae & 우 & $\widehat{\delta}$ & DN & PN & Setae & q & 0 & DN & PN \\
\hline J1 & 12 & 9 & 8 & 6 & $\mathbf{Z 1}$ & 15 & 11 & 10 & 6 & S1 & 22 & 18 & 20 & 18 \\
\hline J1-J2 & 49 & 36 & 39 & 25 & $\mathrm{Z1}-\mathrm{Z2}$ & 48 & 38 & 38 & 28 & S1-S2 & 40 & 32 & 36 & 28 \\
\hline $\mathbf{J} 2$ & 12 & 9 & 12 & 6 & $\mathbf{Z 2}$ & 17 & 14 & 14 & 8 & S2 & 28 & 20 & 24 & 20 \\
\hline J2-J3 & 45 & 38 & 36 & 26 & Z2-Z3 & 42 & 28 & 32 & 24 & S2-S3 & 38 & 35 & 32 & 25 \\
\hline $\mathbf{J 3}$ & 28 & 14 & 10 & 4 & $\mathbf{Z 3}$ & 38 & 28 & 36 & 32 & S3 & 44 & 38 & 42 & 35 \\
\hline J3-J4 & 33 & 26 & 30 & 20 & Z3-Z4 & 38 & 34 & 32 & 24 & S3-S4 & 53 & 43 & 42 & 26 \\
\hline J4 & 34 & 18 & 10 & 4 & $\mathbf{Z 4}$ & 42 & 42 & 48 & 50 & S4 & 43 & 43 & 46 & 43 \\
\hline J4-J5 & 28 & 23 & 22 & 16 & Z4-Z5 & 48 & 43 & 36 & 18 & & & & & \\
\hline J5 & 34 & 16 & 8 & 4 & $\mathbf{Z 5}$ & 28 & 15 & 12 & 14 & & & & & \\
\hline J5-J6 & 32 & 37 & 28 & 20 & & & & & & & & & & \\
\hline J6 & 46 & 48 & 54 & 52 & & & & & & & & & & \\
\hline J6-J6 & 110 & 102 & 100 & 72 & & & & & & & & & & \\
\hline
\end{tabular}




\section{Discussion}

As a result of the analysis of the samples, 86 females, 64 males, 45 deutonymphs and 23 protonymphs specimens of $Z$. saphenus were identified. Samples were analysed under light microscope, their shapes were drawn, measurements of different body parts were taken, their geographic distributions were given and discussed according to literature. In this study, it was determined this species spread in Tunisia before and is recorded from Turkey for the first time. Also, deutonymphs and protonymphs specimens of $Z$. saphenus have been identified as new records from Turkey to world mite fauna. The setae type and location of $Z$. saphenus that we identified from Turkey show similarities with the holotype Z. saphenous Blaszak, 1979. However, body and setae sizes are smaller than the holotype. Length of idiosoma of the holotype $Z$. saphenus is 480/380 micrometers while Turkey samples' are 445/309 micrometers. Setae J6 length of the holotype is 120 micrometers with a distance of 30 micrometers between Z5-J6 while Turkey samples' are 110 micrometers and 18 micrometers, respectively.

\section{Acknowledgement}

We would like to thank Davut Riza BULUT, who collected the litter and moss samples from Kovada Lake National Park (Isparta province).

\section{References}

Blaszak, C. (1979). Systematic studies on the family Zerconidae IV. Asian Zerconidae (Acari, Mesostigmata). Acta Zoologica Cracoviensia, 24 (1), 3-112.

Ghilarov, M. S. (1963). In "Soil Organizm" 1. Doeksen and Von Der Drift, (eds.), North Holland Publishing Company Amsterdam, 255-259.

Hart, C., Morris, C., Baudo, B. \& Degrout, K. (1999). Leaf Litter decomposition and Litter Fauna, Stosktonia 2 (1), 18-21.

Karaca, M., Urhan, R. (2014). Contributions with new records to zerconid mite fauna of Turkey (Acari: Zerconidae), Türkiye Entomoloji Bülteni, 4, 147-155.

Karaca, M., Urhan, R. (2015a). A new record of zerconid mites (Acari, Mesostigmata, Zerconidae) from the Thrace region of Turkey, Turkish Journal of Zoology, 39, 188-190.

Karaca, M., Urhan, R. (2015b). Two new records of the genus Prozercon Sellnick, 1943 (Acari: Zerconidae) from Turkey, Turkish Journal of Zoology, 39, 949-955

Krantz, K. W. (1978). A manual of acarology. 2nd ed., Oregon State Univ., 509.

Martikainen, E. \& Huhta, V. (1990). Interactions between namatods and predatory mites in raw humus soil. Revue D Ecologie et de Biologie du Sol, 27 (1), 13-20.

Mašán, P. \& Fend'a, P. (2004). Zerconid Mites of Slovakia (Acari, Mesostigmata, Zerconidae). Bratislava, Slovak Academy of Sciences, 238 pp.

Petersen, H. \& Luxton, M. (1982). A comparative analysis of soil fauna populations and their role in decomposition processes. Oikos 39, 287-388.

Shereef, G. M., Afifi, M. A. \& El Bishlawy, S. H. O. (1984). Description, life cycle and feeding habitats of Zercon adalicus n. sp. (Acari, Gamasida, Zerconidae). Bulletin of Faculty of Agriculture, Cairo University, 35, 1765-1774.

Urhan, R. \& Ayyıldız, N. (1994a). Two new species of the genus Zercon Koch (Acari, Zerconidae) from Turkey. International Journal Acarology, 19 (4), 335-339.

Urhan, R. \& Ayyıldız, N. (1994b). Türkiye faunası için yeni Zercon C. L. Koch, 1836 (Acari, Mesostigmata, Zerconidae) türleri. Turkish Journal Of Zoology. 18 (1), 53-60. 
Urhan, R. \& Ayyıldız, N. (1996a). Two new species of Prozercon (Plumatozercon) (Acari, Zerconidae) from Turkey. Journal Natural History, 30, 795-802.

Urhan, R. \& Ayyıldız, N. (1996b). Three new species of Prozercon Sellnick (Acari, Mesostigmata, Zerconidae) from Turkey. Acarologia, 37 (4), 259-267.

Urhan, R. \& Ayyıldı, N. (1996c). Zercon bulgaricus Balogh, 1961, a new species for the fauna of Turkey (Acari, Zerconidae). Turkish Journal Of Zoology. 20 (4), 437-440.

Urhan, R. \& Ayyıldı, N. (1996d). Four new species of the genus Zercon Koch, 1836 (Acari, Zerconidae) to the Turkish fauna. Turkish Journal Of Zoology, 20, 293-302.

Urhan, R. \& Ayyıldiz, N. (1996e). Zercon montanus, a new species to the fauna of Turkey (Acari, Zerconidae). Turkish Journal of Entomology, 20 (4), 255-258.

Urhan, R. \& Karaca, M. (2019). A new species of the genus Zercon (Acari, Mesostigmata, Zerconidae) from Kastamonu, Turkey. Acarological Studies, 1(1), 3-10.

Urhan, R. (1997). Two new species of mites of the family Zerconidae from Turkey (Acari, Mesostigmata). Genus, 8 (3-4), 35-742.

Urhan, R. (1998a). Some new species of the family Zerconidae (Acari, Mesostigmata) from Turkey. Journal Natural History, 32, 533-543.

Urhan, R. (1998b). New species of the genus Prozercon (Plumatozercon) (Acari, Zerconidae) from Turkey. Acarologia, 39 (1), 3-9.

Urhan, R. (2001a). New species of zerconid mites (Acari, Gamasida, Zerconidae) from Turkey. Acarologia, 42, 67-73.

Urhan, R. (2001b). A new species of the genus Zercon Koch (Acari, Gamasida, Zerconidae) from Turkey. Zoology in the Middle East, 22, 107-112.

Urhan, R. (2001c). Descriptions of two new species of the genus Zercon Koch (Acari, Gamasida, Zerconidae) from Turkey. Zoology in the Middle East, 23, 107-112.

Urhan, R. (2001d). Two new species of the genus Zercon Koch from Turkey (Acari, Gamasida, Zerconidae). Genus, 12(4), 589-597.

Urhan, R. (2002). New zerconid mites (Acari, Gamasida, Zerconidae) from Turkey. Journal Natural History, 36, 2127-2138.

Urhan, R. (2012). Two new species of Zercon C. L. Koch, 1836 from Turkey. Zoology in the Middle East, 56, 125-132.

Urhan, R. (2013). Two new species of zerconid mites (Acari: Zerconidae) from Giresun Province Turkey). Turkish Journal of Zoology, 37, 172-178. 